\title{
Impact of Outcomes Based Education on Faculty Teaching Index
}

\author{
Mukund V. Kavade ${ }^{1}$, Martand T. Telsang ${ }^{2}$, Sushma S. Kulkarni ${ }^{3}$ \\ ${ }_{1,2}$ Department of Mechanical Engineering, Rajarambapu Institute of Technology, Sakharale, Maharashtra, India \\ ${ }^{3}$ Department of Civil Engineering, Rajarambapu Institute of Technology, Sakharale, Maharashtra, India \\ ${ }^{1}$ mukund.kavade@ ritindia.edu, \\ ${ }^{2}$ martand.telsang@ ritindia.edu, \\ ${ }^{3}$ sushma.kulkarni@ritindia.edu
}

\begin{abstract}
Outcomes based education (OBE) is student centred education. In $\mathrm{OBE}$ at the beginning it is decided what is good or important for the students and then all the resources viz. Curriculum, faculty, library, laboratory, teaching and assessment methods etc. are arranged to achieve that. It is expected that implementation of OBE should improve performance of faculty or the learning satisfaction index of the students. In Rajarambapu Institute of Technology (RIT) OBE is implemented since academic year 2012-13. Students' feedback on the performance of the faculty is collected for all the courses in the semester. It is observed that through these feedback that there is improvement in overall performance of the faculty since implementation of OBE.
\end{abstract}

Keywords: OBE, Learning satisfaction index (LSI). NBA accreditation

\footnotetext{
Mukund V. Kavade ${ }^{1}$

${ }^{1}$ Department of Mechanical Engineering, Rajarambapu Institute of Technology, Sakharale, Maharashtra, India

${ }^{1}$ mukund.kavade@ ritindia.edu
}

\section{Introduction}

National Board of Accreditation (NBA) has changed the model of accreditation from Input - Output to Outcomes based accreditation [1]. Therefore, it is imperative for the engineering institutes to implement OBE. India is permanent member of the Washington accord. All the Universities / Institutes of the member countries of the Washington accord have implemented OBE. In order to make the degrees offered by Indian universities at par with degrees offered by the universities of other member countries of the Washington accord, Indian Universities have to implement OBE. OBE is starting with clear picture of end. It is decided at the beginning itself what is good and important for the students and then all the resources are organized to ensure that it will be achieved.

\section{Student centred approach of OBE}

In OBE freedom is given to faculty to design the teaching and assessment methods to achieve the outcomes. OBE promotes active participation of students in teaching and learning process. In order to achieve the outcomes, faculty designs student centred teaching and assessment methods. A large and rapidly growing body of research confirms the effectiveness of student centred learning in higher education. Relative to students taught traditionally - i.e., with instructor centred lectures, individual assignments, and competitive grading - cooperatively taught students tend to exhibit higher academic achievement, greater persistence through graduation, better high-level reasoning and critical thinking skills, deeper understanding of learned material, more on-task and less disruptive behaviour in class, lower levels of anxiety and stress, greater intrinsic motivation to learn and achieve, greater ability to view situations from others' perspectives, more positive and supportive relationships with peers, more positive attitudes toward subject areas, and higher self-esteem [2].

In Indian engineering institutes generally classes are large. Class strength varies from 60 to 100. In such large class it is imperative to adapt student centred teaching and learning 
methods. This is the only way to give all the students time to speak.

Some of the student centred teaching and assessment methods adapted by the faculty members at RIT are as follows:

i)

Student Teams-Achievement Divisions (STAD) In Student Teams-Achievement Divisions (STAD), teams of four members each are formed. These teams are mixed in performance level, gender, and ethnicity. The teacher presents a lesson, and then students work within their teams to make sure that all team members have mastered the lesson. Finally, all students take individual quizzes on the material, at which time they may not help one another. Students' quiz scores are compared to their own past averages, and points are awarded on the basis of the degree to which students meet or exceed their own earlier performance. These points are then summed to form team scores, and teams that meet certain criteria may earn certificates or other rewards

ii) Jigsaw In Jigsaw students' teams of six members each work on topic that has been split into sections. Each team member reads his or her section. Next members of different teams who have studied the same sections meet in expert groups to discuss their sections. Then the students return to their teams and take turns teaching their teammates about their sections. Since the only way students can learn sections other than their own is to listen carefully to their teammates, they are motivated to support and show interest in one another's work.

iii) Course websites: Faculty members have developed websites for their courses. These websites are used to upload the course details, course materials, assignments, tests, grades, academic material for flipped classes etc.

iv) Project Based Learning is a teaching method in which students gains knowledge and skills by working for an extended period of time to investigate and respond to an engaging and complex question, problem, or challenge.

v) Think-pair-share (TPS) is a collaborative learning strategy in which students work together to solve a problem or answer a question about an assigned reading. This technique requires students to (1) think individually about a topic or answer to a question; and (2) share ideas with classmates

vi) One minute paper A concise note (taking one minute!), written by students (individually or in groups), that focuses on a short question presented by the instructor to the class, usually at the end of the session.

This is the partial list of student centred teaching and assessment methods adapted by the faculty members in RIT.
Impact of implementation of OBE on the performance of faculty members is reflected in a students' feedback on faculty members collected through academic audit.

\section{Academic audit}

\subsection{Purpose of academic audit}

Academic audit is an activity to ascertain the degree of teaching learning process occurring at institute level, which is carried out based on 10 point scale pertaining to teaching dimensions like subject knowledge, Planning and Delivery, Class Management, Communication, Accountability and Concerned for Students . The outcome of audit can be summarized as given below.

a) Identifies the teaching event which occurs poorly

b) Each faculty is rated with teaching index based on her/his performance

c) Positive and Negative observations of each faculty will be identified

\subsection{Procedure for academic audit}

Following steps are involved in academic audit:

i) Dean of academics in consultation with Director, finalize the approved auditors list and decides the academic audit date

ii) Academic co-coordinator in consultation with Dean of Academics devise the methodology to carry out the academic audit

iii) A meeting will be conducted with auditors under the presence of Dean of academics and the guidelines for carrying the audit and past experience of auditors are discussed

iv) Academic co-coordinator after receiving the report prepares the brief report which comprise following points:

a. Average Teaching Index of the Institute

b. Average Teaching Index of each Teaching Dimensions

c. Percentage of faculty distribution in the various range of teaching index

d. Department wise faculty distribution in the various range of teaching index

e. Percentage of Faculty above average teaching Index

f. Department wise Number of faculty lying between 0-50\% in teaching dimensions

v) Academic coordinator after seeking approval of the academic audit report from Dean of academics and Director, the reports are sent to Head of the Department and finally to each faculty through department

vi) Dean of Academics, Director, carry out counseling for the faculty whose teaching index is poor.

\subsection{Guidelines for auditors}

i) Auditor's instruction sheet 
a. Auditors are requested to conduct academic audit within the class room preferably last lecture of the day

b. Criteria for students to participate in auditing process

- Minimum average attendance is $60 \%$

- Students whose parents/relatives are working in RIT are not eligible to participate in audit process

c. Kindly fill all the details in academic audit report especially three positive and negative observations pertaining to concerned staff

d. Deadline for submitting academic audit report is provided to the auditors.

e. Only auditors are required to interact with students and no other members are allowed in auditing process

f. Discuss questionnaires sheet consisting 1-10 questions and explain significance of each.

ii) Computation of teaching dimension: teaching dimensions are computed based on the average responses to the following:

a. Subject Knowledge

b. Planning and Delivery

c. Class Management

d. Communication and English

g. Accountability and concern for student learning

iii) Computation of teaching index

Table 1. Computation of teaching index

\begin{tabular}{|l|l|l|l|}
\hline Dimension & $\begin{array}{l}\text { Score } \\
(\mathrm{Xi}) \text { out } \\
\text { of } 10\end{array}$ & Weights & $\begin{array}{l}\text { Weighted Score } \\
\mathrm{Wi} \text { Xi }\end{array}$ \\
\hline 01 & $\mathrm{X} 1$ & $\mathrm{~W} 1=0.3$ & $\mathrm{~W} 1 * \mathrm{X} 1$ \\
\hline 02 & $\mathrm{X} 2$ & $\mathrm{~W} 2=0.3$ & $\mathrm{~W} 2 * \mathrm{X} 2$ \\
\hline 03 & $\mathrm{X} 3$ & $\mathrm{~W} 3=0.1$ & $\mathrm{~W} 3 * \mathrm{X} 3$ \\
\hline 04 & $\mathrm{X} 4$ & $\mathrm{~W} 4=0.15$ & $\mathrm{~W} 4 * \mathrm{X} 4$ \\
\hline 05 & $\mathrm{X} 5$ & $\mathrm{~W} 5=0.15$ & $\mathrm{~W} 5 * \mathrm{X} 5$ \\
\hline \multicolumn{2}{|l|}{} & $\sum \mathrm{Wi} * \mathrm{Xi}$ \\
\hline
\end{tabular}

\section{Teaching index for last three years}

Academic audit has been conducted for the last three academic years as per the procedure explained 3.2 and teaching indices have been calculated. Senior faculty members from other departments were appointed as auditors. This is a kind of peer assessment where faculty from other department assesses the teaching performance of the faculty.

Teaching indices for last three academic years for Department of Electrical Engineering are given below. Teaching indices have been determined for all other departments as well. Representative data of the Department of Electrical Engineering is reproduced here.

Table 2. Teaching indices for Department of Electrical Engineering

\begin{tabular}{|l|l|l|l|l|l|l|}
\hline $\begin{array}{l}\text { Acad } \\
\text { Year }\end{array}$ & SK & PD & CM & CE & AC & TI \\
\hline $2012-13$ & 2.08 & 1.23 & 0.69 & 1.53 & 0.98 & 6.53 \\
\hline $2013-14$ & 2.60 & 2.39 & 0.80 & 1.21 & 1.25 & 8.26 \\
\hline $2014-15$ & 2.56 & 2.40 & 0.85 & 1.23 & 1.30 & 8.35 \\
\hline
\end{tabular}

SK $=$ Subject knowledge

$\mathrm{PD}=$ Planning and delivery

$\mathrm{CM}=$ Class management

$\mathrm{CE}=$ Communication and English

$\mathrm{AC}=$ Accountability and concern for students

$\mathrm{TI}=$ Teaching index

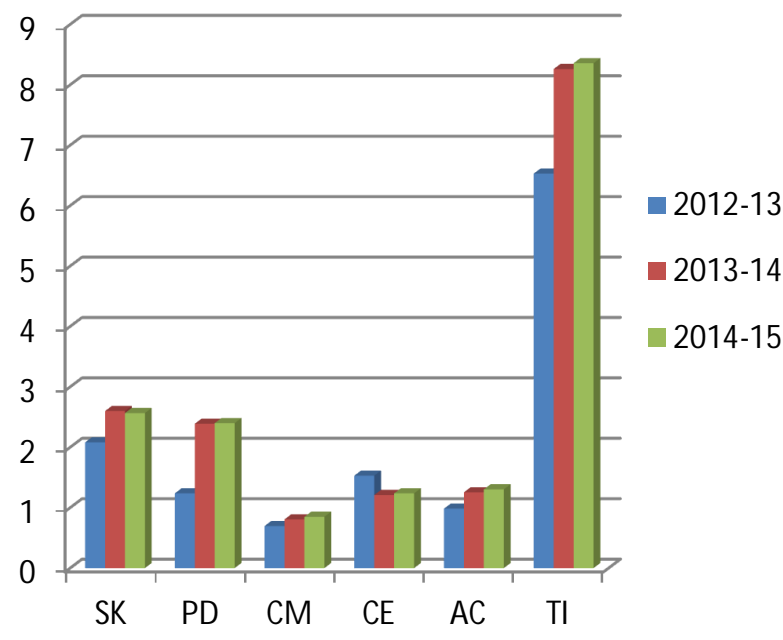
Figure 1 Teaching indices for Department of Electrical
Engineering

Teaching indices for last three academic years for entire institute are presented below.

Table 2. Teaching indices for entire institute

\begin{tabular}{|l|l|l|l|l|l|l|}
\hline $\begin{array}{l}\text { Acad } \\
\text { Year }\end{array}$ & SK & PD & CM & CE & AC & TI \\
\hline $2012-13$ & 2.33 & 1.46 & 0.73 & 1.77 & 1.09 & 7.38 \\
\hline $2013-14$ & 2.56 & 2.39 & 0.78 & 1.11 & 1.27 & 8.11 \\
\hline $2014-15$ & 2.48 & 2.43 & 0.83 & 1.19 & 1.24 & 8.17 \\
\hline
\end{tabular}




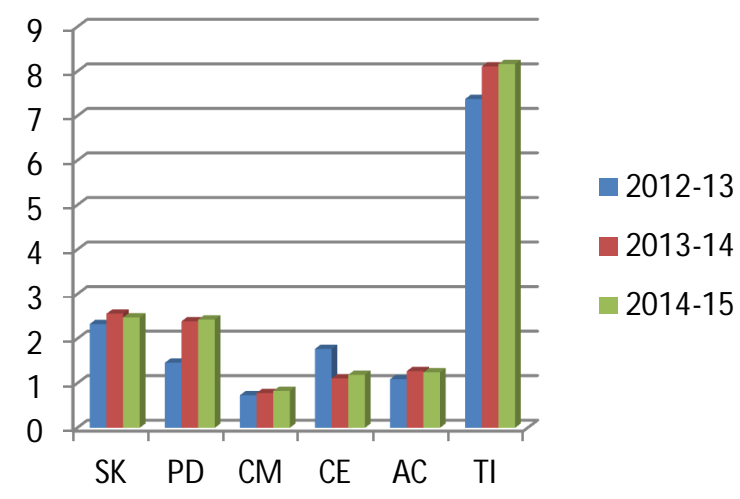

Figure 2 Teaching indices for entire institute

4. Confirmation of the results by statistical analysis Before the results are accepted, it needs to be confirmed that the improvement in teaching index is due implementation of the OBE. It is not due to random error or aberrations or any other factor not considered in this study. One of the statistical tools used for this purpose is analysis of variance (ANOVA) [3].

ANOVA is a technique used to partition the total effect into the effects of individual factors. Effects of individual factors can then be studied to conclude if they are statistically significant or not. Eighteen observations, six from each academic year under study are randomly selected to conduct the ANOVA study. MINITAB 17 software is used for the statistical analysis.

Table 3. Observations used for ANOVA

\begin{tabular}{|l|l|l|l|l|l|l|}
\hline Year & SK & PD & CM & CE & AC & TI \\
\hline $2014-15$ & 2.25 & 2.10 & 0.80 & 1.20 & 1.50 & 7.85 \\
\hline $2014-15$ & 2.70 & 2.55 & 0.90 & 1.20 & 1.35 & 8.70 \\
\hline $2014-15$ & 2.70 & 3.00 & 1.00 & 1.35 & 1.50 & 9.55 \\
\hline $2014-15$ & 2.70 & 2.70 & 1.00 & 1.50 & 1.20 & 9.10 \\
\hline $2014-15$ & 3.00 & 2.40 & 0.75 & 1.35 & 1.13 & 8.63 \\
\hline $2014-15$ & 2.40 & 2.40 & 1.00 & 1.35 & 1.20 & 8.35 \\
\hline $2013-14$ & 2.40 & 2.10 & 0.80 & 1.20 & 1.05 & 6.90 \\
\hline $2013-14$ & 2.70 & 2.40 & 0.90 & 1.20 & 1.35 & 8.70 \\
\hline $2013-14$ & 2.70 & 2.40 & 0.80 & 1.35 & 1.20 & 6.35 \\
\hline $2013-14$ & 2.40 & 2.40 & 0.90 & 1.20 & 1.20 & 6.40 \\
\hline $2013-14$ & 2.40 & 2.40 & 1.00 & 1.05 & 0.90 & 9.68 \\
\hline $2013-14$ & 2.55 & 2.70 & 0.70 & 1.35 & 1.50 & 7.45 \\
\hline $2012-13$ & 2.10 & 1.40 & 0.90 & 2.00 & 1.35 & 7.75 \\
\hline $2012-13$ & 2.40 & 1.60 & 0.80 & 1.50 & 1.05 & 7.35 \\
\hline $2012-13$ & 2.70 & 1.40 & 0.60 & 1.75 & 1.05 & 7.50 \\
\hline $2012-13$ & 2.70 & 1.80 & 0.80 & 2.25 & 1.05 & 8.60 \\
\hline $2012-13$ & 2.10 & 1.40 & 0.70 & 1.50 & 1.05 & 6.75 \\
\hline $2012-13$ & 2.70 & 1.80 & 0.80 & 2.25 & 1.20 & 8.75 \\
\hline
\end{tabular}

\section{Results and discussions}

\subsection{ANOVA}

Following is ANOVA for this study

$\begin{array}{crrrrr}\text { Source } & \text { DF } & \text { Adj SS } & \text { Adj MS } & \text { F-Value } & \text { P-Value } \\ \text { SK } & 1 & 1.8710 & 1.87097 & 2.73 & 0.124 \\ \text { PD } & 1 & 0.1422 & 0.14225 & 0.21 & 0.657 \\ \text { CM } & 1 & 4.1515 & 4.15151 & 6.06 & 0.030 \\ \text { CE } & 1 & 0.0746 & 0.07463 & 0.11 & 0.747 \\ \text { AC } & 1 & 0.0967 & 0.09675 & 0.14 & 0.714 \\ \text { Error } & 12 & 8.2224 & 0.68520 & & \\ \text { Total } & 17 & 17.9419 & & & \end{array}$

Only for the factor $\mathrm{CM}$ (class management) $\mathrm{P}$ value is less than 0.05 (0.03). This indicates that class management is the most significant factor affecting the teaching index of the faculty member. Implementation of OBE has brought considerable improvement in class management. Therefore, improvement in teaching index of faculty is mainly because of implementation of OBE.

\subsection{Adequacy check on the model of analysis}

Before the results are accepted we have to check whether the model is adequate or not i.e. whether error is randomly and independently distributed or not. This is done using residual graphs

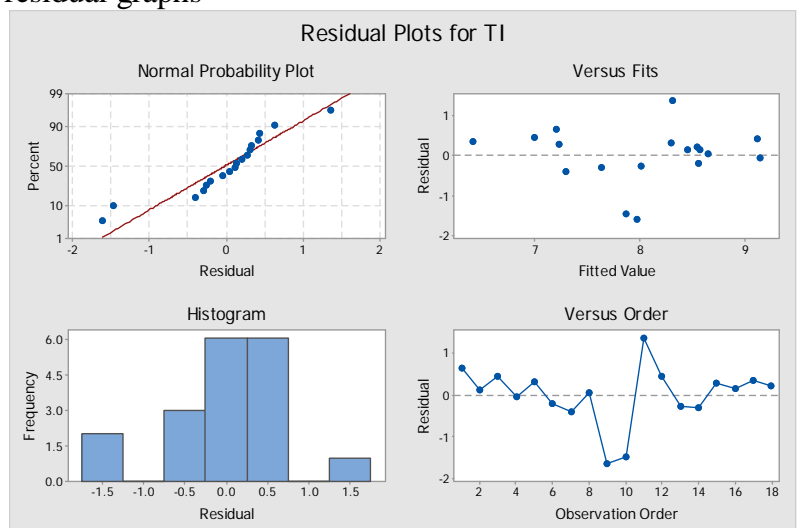

Fig.3 Residual plots for teaching index (TI)

All the four graphs show that model used in analysis is adequate. In normal probability plot all the points lies approximately on a straight line. In versus fits plot, data is well staggered above and below zero line. Histogram is approximately distributed as normal curve. Versus order graph do not show any trend except observation number 9 and 11 are outliers.

\section{Conclusions}

From the academic audit data it can be concluded that there is improvement in the teaching index (performance) of the faculty members. Statistical analysis has confirmed that this improvement is because of implementation of OBE.

\section{References}

[1] National Board of Accreditation manuals

[2] Richard M. Felder and Rebecca Brent, (1994), Cooperative learning in technical courses: Procedures, pitfalls and payoffs, ERIC Document Reproduction Service Report ED 377038

[3] Douglas C. Montgomery, Design and analysis of experiments, John Wiley and Sons 